\title{
GOUTY POLYARTHRITIS: A CASE REPORT IN A TERTIARY SERVICE IN TEFÉ, AM
}

Wuerles Bessa Barbosa1,*

1.Secretaria Municipal de Saúde de Manaus, Manaus (AM), Brazil.

*Corresponding author: wuerlesbessa@gmail.com

\section{BACKGROUND}

Gouty arthritis is a disease of metabolic origin caused by deposition of monosodium urate crystals due to hyperuricemia. It presents with intermittent acute episodes of inflammation and progresses, without treatment, to advanced chronic gout. Generally, the initial crises are monoarticular, mainly affecting the 1st metatarsophalangeal joint, presenting with heat, edema, pain and joint erythema, which may or may not be accompanied by constitutional symptoms such as fever and chills. Definitive diagnosis is made by observing crystals in synovial fluid under a polarized light microscope.

\section{CASE REPORT}

Male, 42 years old, with a history of chronic use of ibuprofen and corticosteroids secondary to intermittent arthralgias in the joints of the knees, ankles, wrists, elbows and left hallux for 8 months. He went to the local emergency service with pain in his left knee, with increased diameter, temperature and the occurrence of scattered erythematous plaques and diffuse skin borders. Laboratory tests were performed, where leukocytes were observed with a value of $35,560 / \mathrm{mm} 3$, neutrophils $91.2 \%$ and uric acid $9.3 \mathrm{mg} / \mathrm{dL}$. Soft tissue ultrasonography showed edema in the subcutaneous tissue and the presence of extra-articular collection with increased synovial fluid. A joint puncture was performed where a turbid brown fluid with leukocytes and an abundance of pyocytes was observed; uric acid equal to $12.9 \mathrm{mg} / \mathrm{dL}$, glucose $7.4 \mathrm{mg} / \mathrm{dL}$ and protein $6.3 \mathrm{mg} / \mathrm{dL}$. With the presumptive diagnosis of septic arthritis and cellulitis, an arthrotomy and antibiotic therapy were indicated. Thus, a new puncture was performed, where monosodium urate crystals were visualized, and the treatment of crises was started with colchicine and, later, with prednisone and allopurinol, evolving with improvement in pain and synovitis in the affected joints.

\section{CONCLUSION}

Gouty arthritis can manifest as a polyarticular disease with systemic involvement in a smaller percentage of patients, therefore, it should be considered as a differential diagnosis in the presence of systemic symptoms.

\section{KEYWORDS}

Gouty, Uric acid, Amazon. 